\title{
A Comprehensive Approach to Power Sector Workforce Development
}

\section{Dr. Nurhidajat Sisworahardjo, University of Tennessee, Chattanooga}

N. Sisworahardjo received his B.S. and M.S. from Institut Teknologi Bandung, Bandung, Indonesia and his Ph.D. from the University of Alabama all in electrical engineering. His research interests are in distributed generation, renewable/alternative energy, power system risk assessment, and optimization techniques in restructured power market. As an educator, he has strong interest in technology utilization in classroom to improve students learning experience.

\section{Dr. Ahmed Eltom P.E., University of Tennessee, Chattanooga}

Dr. Abdul R. Ofoli, University of Tennessee, Chattanooga

Dr. Ofoli received his B.Sc. degree in electrical and electronic engineering from Kwame Nkrumah University of Science and Technology, Kumasi, Ghana, in 1999, and the M.Eng. degree and Ph.D. degree in electrical engineering from Howard University, Washington, DC, in 2002 and 2006, respectively.

During his graduate studies at Howard University, he developed and implemented real-time control algorithms for industrial applications using advance digital control, adaptive control techniques and intelligent control for alternative energy systems, drives, automation and power networks. To show the applicability of these controls to the industrial world, he focused on hardware implementation of most of these control techniques using industrial standard rapid prototyping tools like dSPACE systems utilizing Matlab/Simulink software from Mathworks. He was the recipient of the 2006 IEEE/IAS Transaction Second Prize Paper Award.

Dr Ofoli is currently an Associate Professor at the University of Tennessee, Chattanooga (UTC). Prior to joining the UTC in August 2010, Dr. Ofoli has been working with Cummins Inc at their headquarters in Columbus, IN as a senior controls engineer for four years. At Cummins, he developed and implemented real-time control algorithms and strategies for diesel automotive applications to meet specific control objectives with the major one being the 2010 EPA (Environmental Protection Agency) emission standard for diesel engines. His developed software for emission controls are currently being used on 2010 Cummins Diesel engines and three patents have been filled in regard to that. Dr. Ofoli's area of interest includes power electronics, power system, intelligent controls, renewable energy, and engine controls.

\section{Dr. Edward H. McMahon P.E., University of Tennessee, Chattanooga}

Edward H. McMahon, PhD, P.E. Professor of Engineering Management in the College of Engineering and Computer Science at the University of Tennessee at Chattanooga. He is a He holds a B.S. from Rutgers University and a M.E. and Ph.D. from New York University in Chemical Engineering. He is a registered Professional Engineer in Tennessee. He has nineteen years of industrial experience in industrial process and product development in the detergent, paper, and packaging industries. He teaches capstone design, value engineering and engineering economy at the undergraduate level, and technical innovation and advanced engineering economy in the graduate Engineering Management program. His research interests include product development, technical innovation, entrepreneurship, and design. 


\title{
A Comprehensive Approach to Power Sector Workforce Development
}

\begin{abstract}
The University of Tennessee at Chattanooga, along with its partners, has developed a comprehensive approach to addressing the workforce development needs of the power sector. Funded through a Department of Energy grant the partners are recruiting high school students into power careers, providing two-year and four-year college training, and developing laboratories and graduate curricula tailored to new power and energy technologies. Existing workforce training takes the form of diverse workshop and seminar offerings. The paper describes these programs, their results, and lessons learned from expanding outreach and curricula for power sector constituents.
\end{abstract}

\section{Introduction}

The power sector is dealing with the challenge of an aging workforce, with critical knowledge and experience leaving the industry with each new retiree. The push for a modernized power grid andintegrating new technologies and capabilities has come at the very time that the basic and critical skills required to operate and maintain the existing grid are shrinking.

The challenges and opportunities facing the power industry led the Department of Energy (DOE) to provide grants for workforce development in the electric power sector. This paper describes the efforts of The University of Tennessee at Chattanooga (UTC) as a recipient of one such DOE grant, along with partners Chattanooga State Community College (ChSCC), the Tennessee Valley Authority (TVA), Chattanooga's Electric Power Board (EPB), the local chapter of the IEEE, the Hamilton County Department of Education (HCDE), and the Southeast Tennessee Development District (SETDD). The holistic approach taken by the partnership addresses all aspects of workforce development: recruiting high school students into the power sector careers; training the next generation of technicians, engineers, and managers; and instructing the existing workforce in new technologies.

UTC is ideally situated for collaborations with the power industry. Situated less than a mile from both TVA's operations center and from the headquarters of EPB, the local power distributor which was a recipient of a $\$ 112$ million DOE smart grid grant ${ }^{1}$, UTC regularly pulls from these organizations for adjuncts and research partners. In 2006, UTC gathered a group of leaders from the local power industry to advise and direct efforts to strengthen the power program. Though this close proximity to power sector companies has simplified the growth of power-related curricula, many of the efforts presented in this paper could be applied at more isolated institutions. 
The paper is organized according to the progression of a student through the curricula with at first, discussing recruitment and outreach approaches, followed by a section focuses on two-year programs at ChSCC. The following three sections present undergraduate, graduate, and laboratory efforts, respectively. Continuing education programs are discussed in the section before the paper concludes.

\section{Recruitment and Outreach}

UTC's efforts to recruit students into power sector careers focus on interactions with middle and high schools. Through collaboration with local high school teachers and the local board of education, an energy systems course was developed and approved by the state as a science elective. The course includes science-based instruction on electricity and magnetism and nuclear physics. Following this introduction are modules covering existing energy production, energy distribution, the smart grid, and renewable energy sources. UTC professors serve as guest lecturers on smart grid topics, serving to cement the relationship between the university and the high school. At the end of the course economics and energy audits are covered as a means of evaluating what has been learned. Modules were developed by high school teachers who then "train the trainer" during a summer workshop at UTC that is mandatory for teachers implementing the course. Hands-on projects include winding of a small generator, creation of model power plants, and the construction of a toy-sized electric car.

The energy systems course is currently being rolled out to select high schools in the county with the intention of expanding the number of schools to eventually include high schools across the state. This course is entirely optional for high schools to implement and requires the principal's approval. The program has grown to new schools each year in response to the positive feedback and word-of-mouth from students, teachers, and principals. In contract to the flexibility in the high school curriculum, the course schedule for the middle schools is fixed by the state. Middle school modules are being developed on energy systems that can fit into the existing, stateapproved curriculum.

Additionally, UTC has hired a part-time Outreach Coordinator for growing connections with middle and high schools and the local industry. The Outreach Coordinator is a retired manager with significant power sector experience. The Outreach Coordinator's responsibilities include providing talks about engineering and the power sector to interested K-12 schools. Students in technical and high schools in 20 counties, comprising of 80 high schools, have been reached. Plans are to expand as the program grows. To accomplish this effort, partnerships with other professional organizations and businesses are being pursued. Requests for external support for the recruiting effort resulted in monetary donations from a local firm and donations of water bottles and other giveaways presented to students and teachers during schools visits.

Through the effort of building new ties and strengthening existing relationships, multiple monetary and equipment donations have been obtained. Memorandums of Understanding (MOUs) have been signed with TVA solidifying the relationship and contributing directly to research and educational development ${ }^{2}$. The MOU with TVA's transmission unit provided funds for graduate research in power system protection and committed UTC and TVA to providing 
training opportunities for engineers and students. TVA's nuclear unit committed through an MOU to funding equipment upgrades to a computer laboratory used for power system simulation, with UTC guaranteeing free access to this lab for TVA training.

The Outreach Coordinator position has been integral to these gifts as faculty are frequently to be overextended to solicit donations or seek new industrial relationships outside of research.

Finding interested power sector retirees is highly recommended as such individuals need little, if any, oversight and are more familiar with a company's organization than faculty.

A partner in the DOE grant, the SETDD assists in the recruiting efforts by distributing $\$ 1,000$ Smart Grid scholarships to students at ChSCC and UTC. These scholarships encourage students to pursue energy-related careers and serve to recruit the best students from $\mathrm{ChSCC}$ to UTC.

SETDD's recruiting extends to its participation in the State Energy, Industry, and Construction Consortium (SEICC) that attends career fairs across the state to raise awareness about careers in the power sector.

Among the lessons learned in the process of outreach with high schools was the importance of focusing on receptive teachers. While many teachers welcome professors into their classrooms as guest lecturers, in many cases that was the extent of the relationship with no apparent interest in follow-on activities. However, certain teachers actively grew the relationship, working to arrange campus visits and projects. These visits focused on UTC's senior design projects, with the annual IEEE SoutheastCon's Hardware Competition robot being the most popular. A longer class visit permitted a small soldering project to be completed, with students leaving with a wearable blinking LED. Focusing on a close relationship with a few schools and teachers is believed to produce better results in terms of student recruitment than single visits to many schools. However, as recruitment efforts take years to measure there is not yet data to definitely support the focused approach.

\section{Two-Year Programs}

ChSCC contributions to the program include expanded laboratories and course offerings leading to associate degrees and certificate programs in solar energy technology and a general engineering transfer program that supplies a steady stream of students into UTC's four-year BSEE program. In recent years approximately ten students have transferred to UTC a year. The lab equipment purchased by $\mathrm{ChSCC}$ provides hands-on experience in SCADA, transformers, power system operation, and solar and wind installations. Class projects include energy audits for local companies.

ChSCC partnered with UTC to take the lead in the two year associate degree-based workforce development. The workforce development grant provided ChSCC funds to bring state-of-the-art equipment to the community college and for developing new courses and materials which address the modern power grid. Course offerings lead to associate degrees and certificate programs in Smart Grid, Solar Energy Technology, and the General Engineering transfer program. 
ChSCC expanded laboratories to enhance training in general power system concepts ${ }^{3}$. The Lucas-Nülle Power System Trainers provide an overview and state-of-the-art experience in modern power grid including: SCADA, power generation controls, three-phase power transmission and distribution, and power system protection. As shown in Fig. 1, these trainers demonstrate a fully functional power grid, complete with generators that must be synchronized to the grid before connecting. Models of transmission lines emulate real losses and multiple current and voltage meters emulate the current transformers (CTs) and voltage transformers (VTs) that are polled over SCADA.

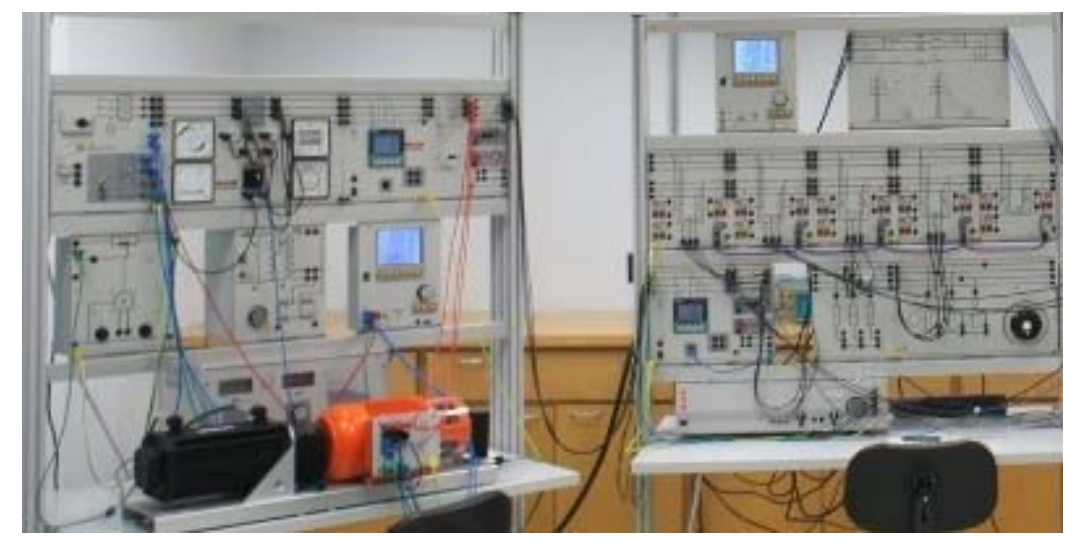

Fig. 1. Chattanooga State Community College power system trainers

The Hampden Three-Phase Transformer laboratory kits give students hands-on knowledge related to power transmission network and distribution systems. ChSCC also received an IncSys Power Simulator online training account so that students can practice the control room operator roles for modern power grid system operation.

One of the advantages of community college courses is that the focus is not only on the academic knowledge, but also on transferring the concepts into practical applications. ChSCC encourages students to gain first-hand real world knowledge and experiences by participating in projects that support local businesses. An energy audit lead by an adjunct professor with smart grid students found a 15\% reduction in a local manufacturer's average monthly utility bill. Students enjoyed the project-based learning experience and the local business benefited from support of the workforce development activity.

The other unique feature in the workforce development partnership is that ChSCC has an ABET accredited general engineering associate degree and transfer program that opens the doors of four-year college to two-year students. This program is first of its kind accredited in the nation. ChSCC prepares students in the first two years of fundamental mathematics, English and general engineering courses, while providing students with more hands-on experiences on basic electric circuits and power systems.

ChSCC and UTC possess a close relationship that is evolving to ease the transition of students transferring from the two-year institution. ChSCC and UTC developed an "open lab" policy that allows students from both institutions to be able to use laboratory equipment at each other's campus. Students from ChSCC complete lab assignments in UTC's electrical machines 
laboratory, serving to recruit students into UTC's four year program while exposing the students to equipment not available at $\mathrm{ChSCC}$. With limited resources, $\mathrm{ChSCC}$ is able to focus on different aspects of the training and maximize the learning outcomes. ChSCC now supplies ten or more students into UTC's Electrical Engineering junior level programs each academic year. That is almost half of the total number of students in the EE junior level programs.

Multiple UTC faculty members sit on the advisory board for ChSCC's general engineering program. By meeting at the start of every semester, each institution can be updated on the changes at the other, ensuring that any planned or proposed curriculum changes are mirrored at the neighboring school. Issues students encounter while negotiating the transfer process are discussed. An articulation agreement exists between UTC and ChSCC negating the need for students to petition individual courses. Further cementing the relationship, UTC graduates have become adjunct professors at $\mathrm{ChSCC}$ and $\mathrm{ChSCC}$ instructors have become UTC graduate students. UTC has begun further outreach with nearby community colleges to build similar relationships.

Lessons learned from interactions between the institutions include the importance of constant communication both between the institutions and with transfer students. The registration and orientation process for transfer students can be significantly different from that of freshmen. As freshmen advising is more flexible in that more time exists to correct mistakes, transfer student schedules must be correct from the start. By expanding articulation agreements the petition burden for transfer students can be minimized. Sending professors from the four-year institution to the community college to speak with potential transfer students was well received. Students asked many questions and responded positively by meeting a professor at their future institution.

\section{Bachelor's Degree}

UTC offers a traditional four-year BSEE degree. In contrast to many schools, which pared back power-related course offerings during the tech boom, UTC retained required courses in electrical machines and power system analysis and design. The award of the DOE workforce development grant enabled the expansion of power offerings, addition of new laboratories, and further collaboration with the local industry.

A curriculum revision that was completely implemented in fall of 2013 and underwent a second revision and was fully implemented in fall of 2015 sees the addition of EE-specific electives tailored to the energy and power area ${ }^{4}$. A key component of the curriculum revision is the advancement of the Electric Energy Conversion lecture and laboratory and the Power System Analysis and Design lecture ahead one semester, to both be in the junior year. This permits seniors to leverage these courses as pre-requisites to take the more advanced electives. These new courses complement the existing Power System Protection elective, which has proved popular among students and industry, and include:

- Linear Controls and Drives Lab - This laboratory introduces students to components in an electrical drive system, building real-time control systems using Matlab/Simulink interface, PI and dual loop algorithms as applied to servomotor position control and state variable feedback control applications using DC, induction, and permanent magnet $\mathrm{AC}$ motors. 
- Introduction to Smart Grid - This course exposes students to the evolution of existing power grid to the smart grid, role of telecommunication in efficient transmission, intelligent metering and sensors networks. Security, reliability, and economic aspects. The objective of this course is to provide students with emerging concepts, technologies, applications, business models, and the related trade-off decisions involved in transforming the nation's century-old, centralized power grid into being more climate and renewable energy-friendly.

- Sustainable Electric Energy Systems - In this course, students explore the scientific and technological principles and practical conversion applications of sustainable electric energy sources, the fundamental concept of electric power system, distributed generation, and energy storage technologies. The objective of this course is to provide students with a foundation in the technological and economic fundamentals of important and emerging sustainable energy technologies.

- $\quad$ Setting and Testing of Digital Relays - Provides exposure to test equipment and procedures when testing modern microprocessor-based multifunction transmission system protection equipment. Includes ccalculating test quantities, making connections between relay and test sets, and analysing results including fault records.

- Power Electronics (lecture and lab) - Introduces power semiconductor devices and power electronic converters, including single-phase and three-phase ac/dc rectifiers, ac voltage controllers, ac/dc converters and dc/ac inverters.

- Smart Distribution Systems - Provides exposure to distribution system operation, protection coordination, and maintenance. The students are also exposed to data management analysis, disturbance analysis. In this course, students gain first-hand experience from experts in their fields (telecommunication, protection, distribution network, etc.) who come to class as invited speakers.

In some cases these courses were developed largely or in part by adjunct faculty who are practicing engineers in the local power industry who then went on to teach the course. The students gain real-world knowledge and, in some cases, these students are recruited by the adjunct to work for his or her company.

Like many institutions, the number of hours in UTC's BSEE is capped by the state at 128 . Further restrictions are added by the University which require 21 hours of general education courses (excluding math and science requirements that count towards the engineering curriculum). To make the most of the remaining hours in the presence of an ever expanding body of knowledge, power-related projects were integrated into the College's two-semester senior design projects ${ }^{5}$. Student projects include the design of a substation, a building-wide energy monitoring system, and a wind turbine suitable for third world countries. As a mechanism to extend education beyond the 128 hour limit, UTC is exploring the addition of an undergraduate certificate in power engineering.

\section{Graduate Programs}

Multiple graduate-level courses have been developed to address the pressing needs of the power sector, including Power Systems Transients, Smart Distribution System, Introduction to Smart Grid, Sustainable Electric Energy Systems, and Network Communications. These courses 
complement the existing graduate power curriculum which includes courses in Power System Analysis and Design, Power System Protection, Setting and Testing of Digital Relays, and Power System Operation. Where possible, these courses are offered cross-listed as undergraduate lectures (see Section IV). Many of these courses were developed hand-in-hand with industry experts. Taken as a whole, the graduate power offerings address the areas of most pressing concern to the power industry.

In addition to a traditional master's degree, the Department of Electrical Engineering has developed four-course graduate certificates in power-related areas. These certificates require the students take a required core of two courses and select remaining hours from a specified set of electives to fill the required 12 hours. A fifth certificate was created in partnership with Engineering Management department. Current certificates, along with core required courses, include:

- Sustainable Electric Energy Certificate - Sustainable Electric Energy Systems and Engineering Analysis of Renewable Energy Sources;

- Power System Protection Certificate - Power System Protection and Setting and Testing of Digital Relays;

- Power System Distribution Certificate - Introduction to Smart Grid and Smart Power System Distribution;

- Smart Grid Certificate - Introduction to Smart Grid and Networking

- Power System Management Certificate (in cooperation with the Engineering Management department) - Power System Operation, Power System Protection, Technical Project Management, and Advanced Engineering Economy,

When the certificates were initially conceived, graduate school regulations permitted students to leverage all hours required for a graduate certificate towards the completion of a master's degree. The majority of the certificates awarded went to master's students who completed the requirements for both programs in 30 hours with a careful selection of courses. A recent modification to the graduate catalog limits the hours that can count towards both a certificate and a graduate degree to six hours and has negatively impacted certificate enrollment. One lesson learned is the importance of approaching the appropriate governing body to inquire about potential regulation changes that might affect new programs during planning stages.

UTC's Engineering Management program offers a graduate engineering management degree with a concentration in Power Systems Management. This curriculum instructs engineers in the technical aspects of the power-sector while providing them with project management and leadership skills. Five courses in engineering economy, management, and leadership comprise the core, with an additional five courses chosen from a list of power system electives. As with all UTC engineering management graduate degrees, students must complete a three credit hour capstone project related to their field. To provide a power industry perspective in the conventional engineering economy course, outside experts from TVA are brought in to provide guest lectures.

Online offerings of engineering management courses have proved popular, with distance attendance roughly equal to traditional classroom attendance. As a result of the successes in the engineering management program, electrical engineering is adding online sections to its graduate 
power offerings. With the exception of two laboratory-intensive graduate courses, the intention is to have the entire power curriculum available online. It is expected that the graduate certificate programs will be attractive to working professionals.

\section{Laboratories}

\section{Smart Grid and Protection Laboratory}

UTC's strong relationship with TVA enabled the continual growth of its power protection laboratory ${ }^{6}$. The laboratory has evolved into a state-of-the-art facility to train the current workforce in use of advanced technology for power applications and to prepare undergraduate and graduate students for future power industry needs. The laboratory has been utilized by companies to train their workforce and to showcase their products to customers. Graduate students leverage the equipment for research topics chosen to benefit TVA ${ }^{7,8}$.

The laboratory features the latest in power protection relays and test equipment, including transmission line protection relays with 61850 networked communications. Line protection relays from multiple vendors and a relay test set comprise each of the seven stations. A generous donation of home and commercial smart meters are being integrated as well. A Real Time Digital Simulator (RTDS) purchased under the DOE grant enables the testing of relays against a simulated power grid in real time.

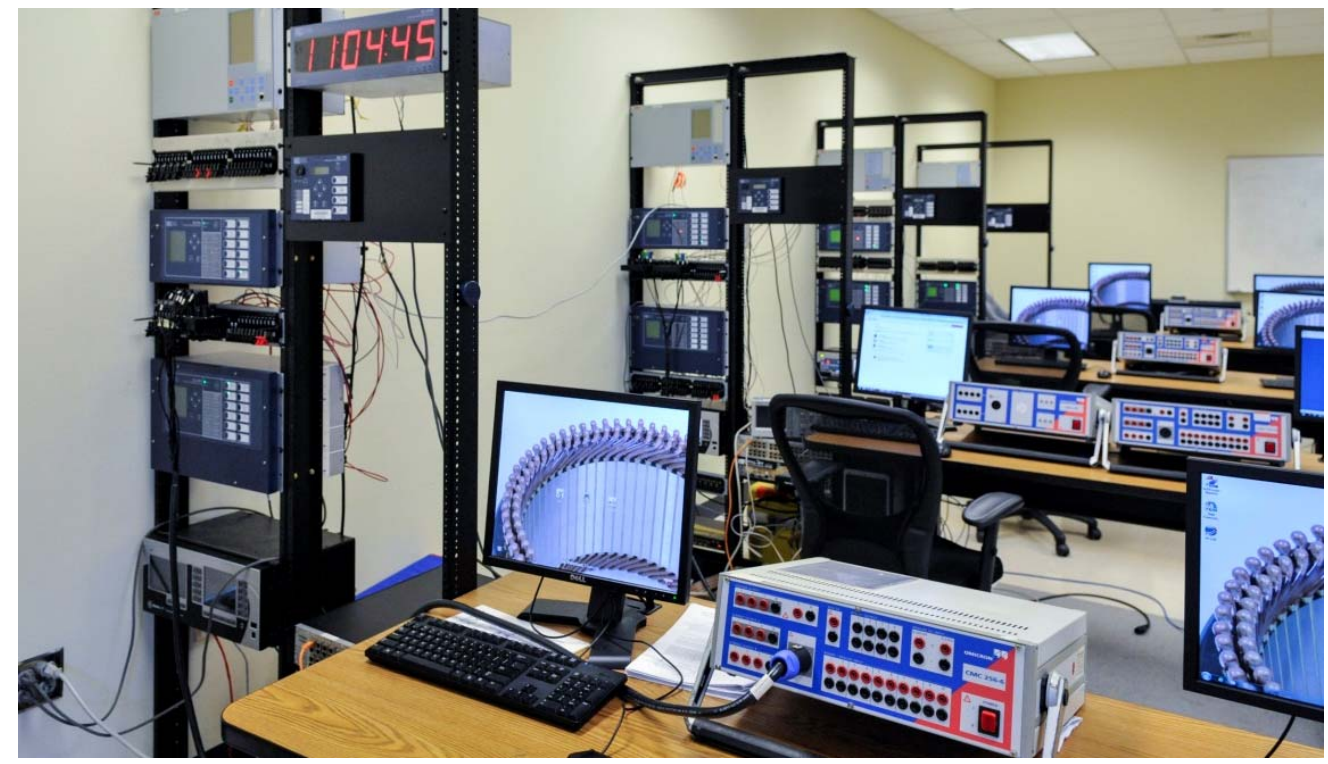

Fig. 2. Smart Grid and Protection Laboratory

The laboratory supports directly or/and indirectly various undergraduate and graduate classes which include Control Systems Analysis and Design, Power Electronics, Electrical Machinery, Microprocessors Applications, Power System Analysis and Design, Power System Protection, and Setting and Testing Digital Relays. 
As depicted in Fig. 2, the laboratory features state-of the-art relays donated from well known relay manufactures such as $\mathrm{ABB}, \mathrm{GE}$, and Schweitzer Engineering Laboratories (SEL). Line distance relays include the SEL-421, GE D90+, and ABB REL670. The ABB TPU 2000R and the GE T60 comprise the transformer protection relays. These relay stations are set up with breaker simulators, GPS units, Phasor Measurement Units (PMUs), and residential smart meters. Relay testing is conducted using donated Omicron and Doble test equipment. A RTDS, Opal-RT, is used for dynamic relay testing, IEC 61850 testing, and real time simulation of the power system. The GPS units are available for time stamping data received from PMUs and relays. The lab has been featured in a prominent industrial trade publication ${ }^{9}$ and is set to double in size with a $\$ 1$ million equipment donation from Doble Engineering.

The Setting and Testing Digital Relays laboratory course is taught by faculty and experienced engineers from industry, with TVA routinely supplying adjuncts to teach actual industry practice to a diverse group including traditional graduate students as well as practicing engineers.

To expose students to a wide variety of equipment present in the smart grid, a new laboratory course was developed with specific assignments including:

- Phasor Measurement Unit setup - Using the SEL-411L relay, a GPS time source, and a test set, configure and test PMU functionality.

- $\quad$ Testing of Smart Meters - Simulate a dynamic load with a test set, monitoring the load with an SEL-735 meter.

- RTDS Model Creation - Develop and simulate a transmission line within the OpalRT RTDS.

- $\quad$ RTDS Relay Testing - Program the OpalRT RTDS with a simulated transmission system using the Simulink interface. Use a current and voltage amplifier to interface the RTDS to an SEL-411L relay and simulate a fault, verifying the relay reacts appropriately.

\section{Power Simulation Laboratory}

Power Simulation Laboratory is a state-of-the-art learning environment created as the result of a three-way partnership among TVA, Operation Technology, Inc. (OTI), and UTC. This laboratory contains the latest in electrical power simulation system design and analysis software known as ETAP. Students are able to use computer-based simulation software to perform power flow, short circuit studies, and other power system simulation studies. This laboratory supports various upper level undergraduate and graduate courses such as Power System Analysis and Design, Electrical Machines, Power System Operations, Transient in Power Systems, Power System Protection, and Sustainable Electric Energy Systems.

The Power Simulation Laboratory facility is also used to host practitioners and engineers to conduct workshops and seminars to maintain and improve their knowledge and expertise. One of the power system planning projects assigned in Power System Analysis and Design course for undergraduate and graduate students uses the ETAP simulation software to determine an adequate electric power for a new industrial park to meet the demand of its industry and to support the expected load growth. Another project involved the use of the software to model the power distribution system of the engineering building. 
The lab also includes CAPE (Computer-Aided Protection Engineering) software built for engineers responsible for protection of high voltage transmission systems and distribution systems within electric power utilities.

\section{Electric Machines Laboratory}

This laboratory was furnished with the help of a grant from TVA and the Electric Power Research Institute (EPRI). It consists of six Lab-Volt Electromechanical Training System stations that support two undergraduate courses.

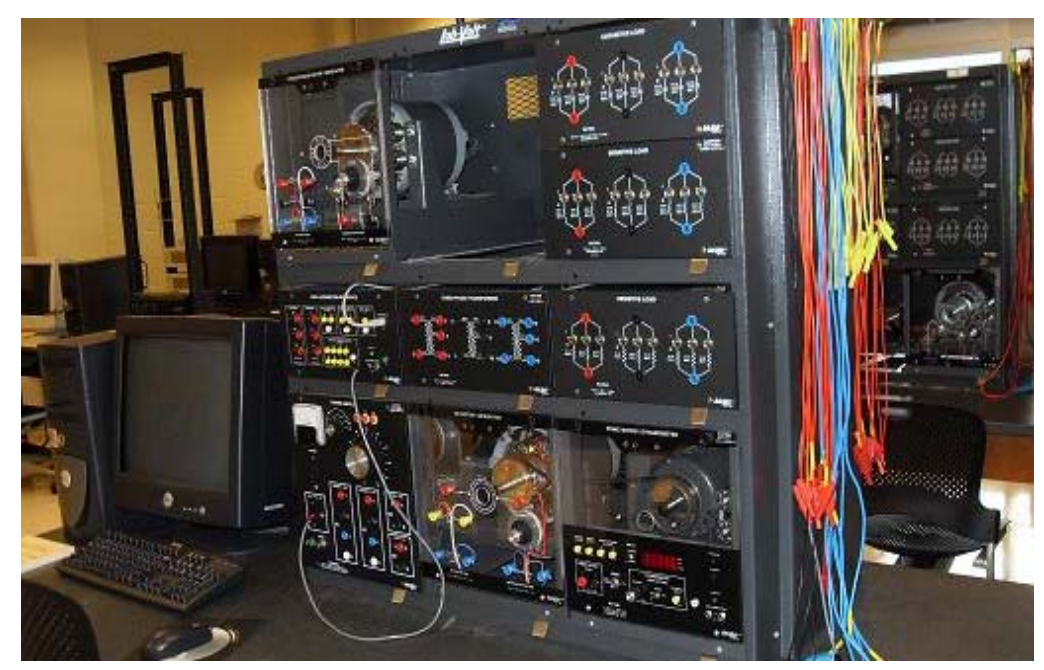

Fig. 3. Configurable Lab-Volt station with data interface

Each of the Lab-Volt stations, one of which is shown in Fig. 3, features multiple motors and loads and a data acquisition and control interface to the neighboring computer. Students are able to conduct various experiments on single- and three-phase power with resistive and reactive loads; transformer polarity, parameters, and characteristics; and AC and DC machine behavior and loading characteristics.

\section{Power Electronics Laboratory}

UTC is undergoing a restructuring effort to make power electronics and electric drives more appealing to students and also provide hands-on experience in practical power electronics applications. The power electronics laboratory is built around a reconfigurable circuit board, termed the power-pole board, along with accessory daughter-boards designed by the University of MSTA, as shown in Fig. 4. Details on the equipment and the associated lab experiments are available in ${ }^{10}$.

The board can be configured to work as a buck, boost, buck-boost, flyback or forward converter. The board can also be operated in voltage/current feedback mode using an external control circuit mounted on a daughter board. In addition to the power board, high wattage resistors, power supplies, a multi-meter and differential probes were obtained to create a student work station. Currently, there are six work stations for the power electronics laboratory at UTC. There 
is a plan to increase the stations to nine due to high student enrollment in this class since its inception in the spring of 2011. Students have a choice between two advanced electronics courses, with Power Electronics proving significantly more popular than the existing advanced electronics course.

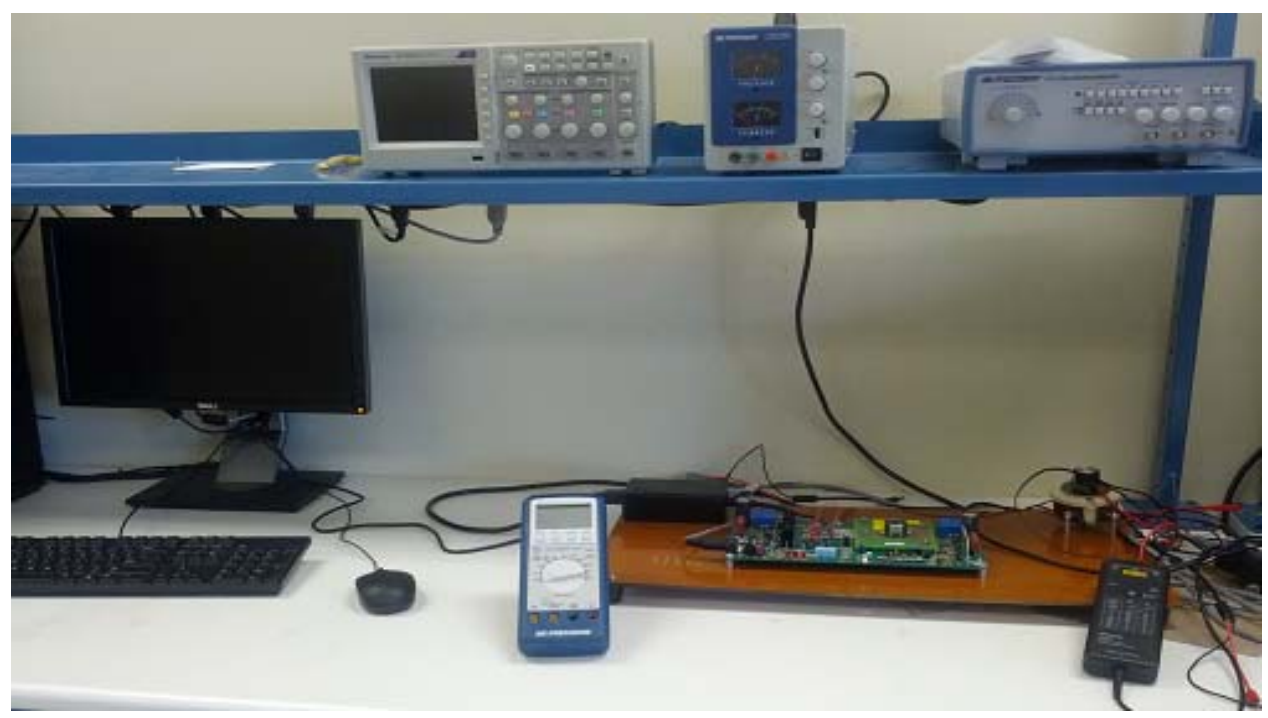

Fig. 4. Typical station from the power electronics laboratory

\section{Electric Drives Laboratory}

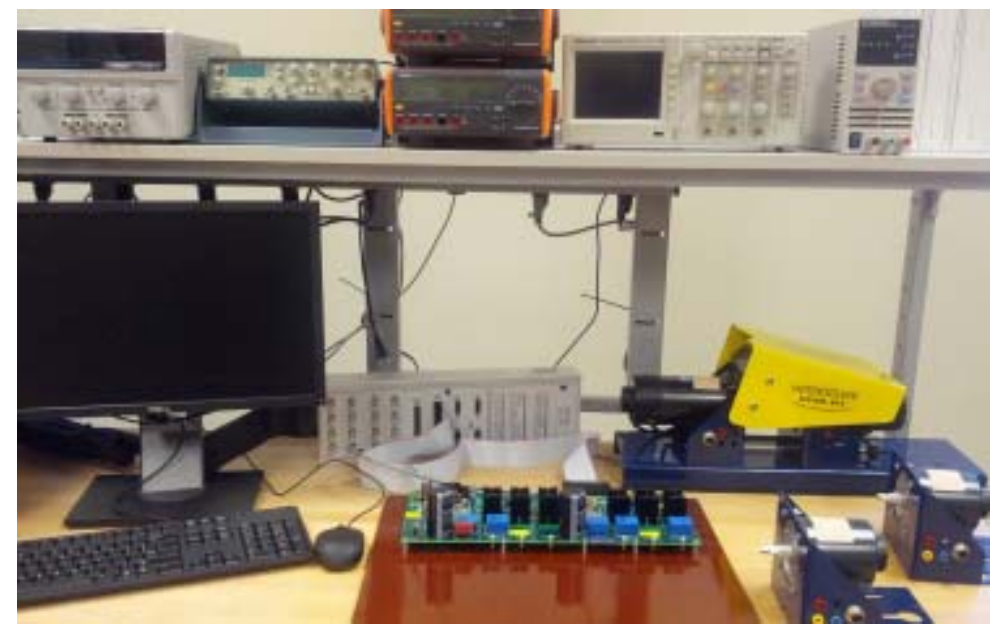

Fig. 5. Typical station from the electric drives and controls laboratory

Fig. 5 shows the hardware set used for the electric drives lab station which consists of a motor coupling system, power electronics drive board, and a DSP-based controller card. The motor coupling system contains the motor used for characterization or control. The system has a mechanical coupling arrangement to couple two electric machines. The motor under testing could be a DC motor, a three-phase induction motor, or a three-phase permanent-magnet AC 
(PMAC) motor. The motor requires a controlled pulse-width-modulated (PWM) voltage to run at controlled speed or torque that is generated by power electronics drive board.

\section{Continuing Education}

UTC offers a wide assortment of seminars, workshops, and "lunch "n learns" that have proved very popular with the local power industry. Since October, 2010, over 1,000 industry professionals and engineering students have attended these events. Many times, sponsorship by TVA, EPB, SEL, or other industry partners covers the entire cost of attendance. Feedback from participants indicates the seminars are an extremely effective mechanism for outreach and addressing the continuing education needs of an aging workforce.

Transformer diagnostics was the most requested topic, with utilities and distributors alike attending. These seminars have served to solidify the relationship between UTC and the regional power industry with attendees coming from multiple states. The most popular day-long seminar topics include:

- IEC 61850

- Diagnostic Measurements on Power Transformers

- Annual Smart Grid Workshop

- Distribution Automation

- Transformer Diagnostic Workshop

Given the shrinking training budgets of many organizations UTC strived to keep the cost of the events low and, in many cases, free by leveraging corporate sponsorship of the event. With no cost to register and no monetary motivation to cancel a registration, "no shows" were a constant concern. It was found that frequent email communication with registrants reduced the number of "no shows," enabling a more accurate estimate of attendance for planning purposes.

For several of the larger events, live video streaming over the Internet was offered. This allowed a more diverse audience to attend, but complicated the logistics of offering the event.

Lessons learned in the years of hosting power-related events include the importance of offering Professional Development Hours (PDHs) towards professional registration. Advertising was accomplished initially via industry contacts and relevant power engineering email list servers. The registrants for each event were then added to a database that is used for advertising. Larger industry organizations generally have codified educational requirements for advancement, such as TVA's Engineering Graduate Progression Plan, or professional development requirements for certain job functions. By tailoring continuing education courses to meet these requirements, attendance increases and the relationship between industry and academia is strengthened.

\section{Results}

Measurement of the effects of these endeavors has been made quantitatively, through enrollment, seminar attendance, and donations, and qualitatively, through surveys and feedback. 
Enrollment in electrical engineering at UTC is shown in Fig. 6 . The years on the $\mathrm{x}$-axis indicate the year at the start of the fall semester. The growth of the undergraduate program between 2008 and 2011 was $72 \%$, compared with a $10 \%$ growth in EE undergraduate enrollment during the same period for American universities ${ }^{11}$. It can be difficult to attribute a cause to enrollment fluctuations and the economic downturn undoubtedly played some significant role in the enrollment jump seen in 2009. While the close interaction with industry has existed for more than a decade, several of the efforts described in this paper began fall semester of 2010 . We attribute the sustained growth to these curriculum changes and outreach that started to take effect in 2010 .

Graduating seniors are surveyed every spring to provide a metric for the health of the program with specific questions related to curriculum, facilities, and faculty. Comparing the relevant survey results for the seniors graduating in May 2010, just before the DOE grant began, to those graduating in May 2013 reveal significant increases in responses related to laboratories and overall program satisfaction as shown in Table 1.

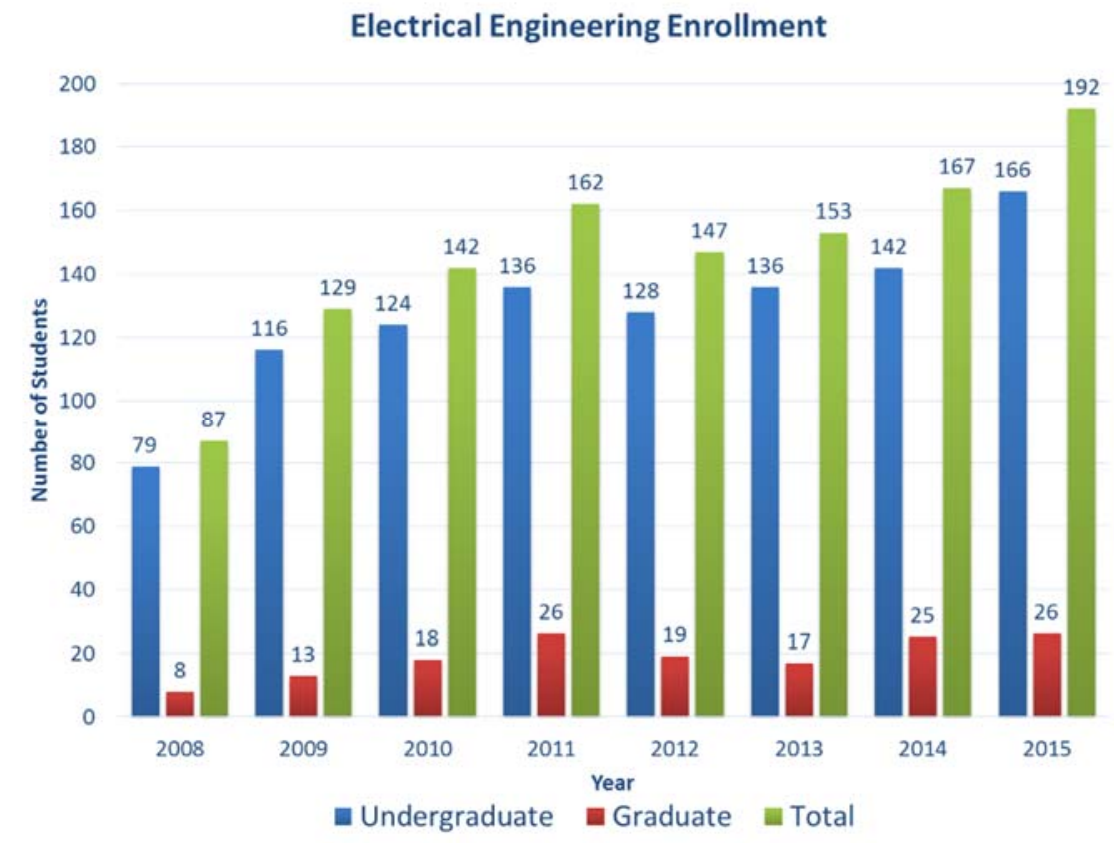

Fig. 6. EE undergraduate (UG) and graduate (Grad) enrollment 2008 - 2015

Table 1: Senior Exit Survey Comparison (4-point scale)

\begin{tabular}{|l|c|c|c|}
\hline \multicolumn{1}{|c|}{ Statement } & $\mathbf{2 0 1 0}$ & $\mathbf{2 0 1 3}$ & \% Change \\
\hline The lab facilities are excellent. & 2.6 & 3.3 & $+27 \%$ \\
\hline $\begin{array}{l}\text { I would recommend this } \\
\text { program for other students. }\end{array}$ & 2.6 & 3.3 & $+27 \%$ \\
\hline
\end{tabular}

Another metric for gauging industry involvement and "buy-in" is through donations. Beginning in 2010, UTC leveraged the DOE grant and its ties to local industry to solicit equipment, 
software, and grants from relevant power-sector companies such as Doble Engineering, Operation Technology, Inc., OMICRON, Schweitzer Engineering Laboratories, and TVA. The total value of the received donations and industry-funded research grants in this three-year period exceeds $\$ 1.75 \mathrm{M}$, almost double the value of donations the department had received in the previous decade.

\section{Conclusions}

By leveraging a grant from the DOE, UTC, ChSCC, and partners addressed the workforce development needs of the power sector through a comprehensive program of recruitment, outreach, academic programs at the two-year, four-year, and graduate levels, and continuing education seminars. Partnerships between academia and industry were critical to the expansion of power-focused curricula at UTC and ChSCC and resulted in donations of money, equipment, and time that led to successful development of multiple labs and courses.

Lessons learned include the importance of involving power-sector retirees and other professionals in the recruitment and outreach activities. It was found that high schools were open to incorporating power-related topics if the proper curriculum approval processes were followed. Seminars, co-sponsored by industry, were an excellent method to address existing workforce training and strengthened relationships between industry and academia. Taken as a whole, these efforts have resulted in increased enrollment and visibility within the local power sector.

\section{References}

[1] Department of Energy Office of Electricity Delivery \& Energy Reliability. (2012, July). Smart Grid Investment Grant Program - Progress Report. [Online]. Available: http://energy.gov/node/377899

[2] WRCB. (2012, Nov. 14). TVA supports UTC's smart grid research. [Online]. Available: http://www.wrcbtv.com/story/20097983/tva-supports-utcs-smart-grid-research

[3] W. Wan and S. Craven, "Towards State-Of-The-Art Power System Training: DOE Smart Grid Partnership with UTC", National Coalition of Advanced Technology Centers (NCATC) National Fall Conference, Chattanooga, TN, Oct. 6, 2011.

[4] “Electrical Engineering, B.S.E.E.”, 2013-2014 Undergraduate Catalog, The University of UTC, 2013. [Online] Available: http://catalog.utc.edu/preview_program.php?catoid=10\&poid=1286\&returnto=233

[5] N. Sisworahardjo, A. Ofoli, S. Craven, and A. Eltom, "State-of-the-Art Laboratories for Training the Modern Power Workforce," IEEE Power \& Energy Society General Meeting, Vancouver, BC Canada, 21-25 July, 2013.

[6] A. Eltom and R. Harnchotipun, "Microprocessor-based relay laboratory with industry support," IEEE Power Engineering Society Summer Meeting, Vol. 3, pp. 1457 - 1461, 2002.

[7] J. Ruiz, "Performance Comparison of a Permissive Overreach Transfer Trip (POTT) Scheme over IEC 61850 and Hard-wire," Master's thesis, Dept. EE, University of Tennessee at Chattanooga, Mar. 2012.

[8] N. Sichwart, "Transformer Load Tap Changer Control Using IEC 61850 Goose Messaging," Master's thesis, Dept. EE, University of UTC, Mar. 2012.

[9] R. Bush, "Universities and Utilities Unite," Transmission and Distribution World, Jan. 2013. [Online] Available: http://tdworld.com/business/universities-and-utilities-unite

[10] N. Mohan, W. P. Robbins, P. Imbertson, T. M. Undeland, R. C. Panaitescu, A. K. Jain, P. Jose, and T. Begalke, "Restructuring of First Courses in Power Electronics and Electric Drives that Integrates Digital Control,” IEEE Transactions on Power Electronics, vol. 18, no. 1, pp. 429-437, January 2003. 
[11] B. Yoder, "Engineering by the Numbers," American Society for Engineering Education, 2012. [Online] Available: http://www.asee.org/papers-and-publications/publications/college-profiles/2011-profileengineering-statistics.pdf 